\title{
Reflets
}

Revue ontaroise d'intervention sociale et communautaire

\section{Le centre communautaire de santé mentale de Prescott-Russell}

\section{Marlène Falardeau}

Volume 1, numéro 1, printemps 1995

Des pratiques à notre image : défis et ressources

URI : https://id.erudit.org/iderudit/026067ar

DOI : https://doi.org/10.7202/026067ar

Aller au sommaire du numéro

Éditeur(s)

Reflets : Revue ontaroise d'intervention sociale et communautaire

ISSN

1203-4576 (imprimé)

1712-8498 (numérique)

Découvrir la revue

Citer cet article

Falardeau, M. (1995). Le centre communautaire de santé mentale de Prescott-Russell. Reflets, 1(1), 219-222. https://doi.org/10.7202/026067ar

Tous droits réservés (C) Reflets : Revue ontaroise d'intervention sociale et communautaire, 1995
Ce document est protégé par la loi sur le droit d'auteur. L'utilisation des services d'Érudit (y compris la reproduction) est assujettie à sa politique d'utilisation que vous pouvez consulter en ligne.

https://apropos.erudit.org/fr/usagers/politique-dutilisation/ 


\section{Le centre communautaire de santé mentale de Prescott-Russell}

Marlène Falardeau

Ergothérapeute, Centre communautaire de santé mentale Prescott-Russell

\section{Fondation du Centre}

Le Centre communautaire de santé mentale de Prescott-Russell (CCSMPR) a pignon sur rue à Rockland, une petite ville située à $25 \mathrm{~km}$ à l'est d'Ottawa, dans les comtés unis de Prescott-Russell. La création du centre, en juin 1987, a été l'aboutissement de deux ans de travail de mise en oeuvre faisant suite à une initiative de demande de subvention entreprise par l'Hôpital Montfort, un établissement de soins de santé situé à Ottawa.

À cette époque, le Ministre de la santé venait de renouveler son appui aux services communautaires de santé mentale. L'Hôpital Montfort n'était donc pas sans savoir que le ministère de la Santé privilégiait les programmes et les services s'appuyant sur l'ensemble des ressources communautaires plutôt que les services hospitaliers plus coûteux, pour actualiser ses priorités de promotion et de maintien de la santé. De plus, le gouvernement de l'Ontario avait déjà accordé son appui à un programme connu sous le nom de health styles, qui avait sensibilisé plus de six cent cinquante personnes aux façons de prendre soin de leur santé et aux changements à apporter à leur style de vie pour atteindre un meilleur niveau de santé physique et mentale.

Lors de la préparation du projet, l'équipe de l'Hôpital parrain avait aussi consulté quelques études épidémiologiques afin de 
Reflets

préciser les caractéristiques et les besoins des populations cibles. Des études avaient démontré que $10 \%$ des personnes dans un bassin de population d'environ 60000 avaient dû avoir recours à des services de santé mentale dans des hôpitaux de Cornwall et d'Ottawa. De plus, une enquête menée auprès des médecins des deux comtés désignés avait révélé que plusieurs des répondantes et répondants déploraient la pénurie de services professionnels en santé mentale.

\section{Le service}

Par l'entremise de deux points de service (un principal à Rockland et une succursale à Casselman), le CCSMPR offre des services aux personnes de 16 ans et plus qui habitent dans Prescott-Russell et qui présentent des problèmes psychiatriques, surtout de nature psychosociale. Ces personnes se présentent au CCSMPR d'ellesmêmes ou elles y sont référées par les centres de santé, leurs médecins, leurs familles, leurs amis.

La clientèle qui fait appel aux services du CCSMPR consulte généralement à cause de troubles anxieux, (anxiété généralisée, phobie sociale, phobie spécifique, agarophobie, crises de panique, stress post-traumatique, etc.) de troubles affectifs (dépression réactionnelle, état dépressif, etc.) ou de troubles de la personnalité.

L'équipe de ressources professionnelles comprend un coordonnateur exécutif, une secrétaire-réceptionniste, une ergothérapeute, une infirmière, une psychométricienne, une travailleuse sociale et un psychiatre consultant.

Le CCSMPR offre un service d'accueil du lundi au vendredi, de 8 h30 à 16h30. Tous les membres de l'équipe assument, à tour de rôle, les responsabilités liées à l'accueil, telles l'intervention en situation de crise et la consultation suite aux demandes de service.

Les services offerts au centre, à domicile ou dans divers locaux communautaires, comprennent: l'évaluation, la consultation, la thérapie individuelle, de couple et de groupe, ainsi que 
des programmes de prévention et d'éducation. Ces derniers, en plus d'être offerts aux gens en difficulté et à leurs proches peuvent s'adresser à certains groupes-cibles ou à la population en général. Des présentations traitant notammment de stress, de burn-out et de suicide ont été offertes à des groupes qui en avaient fait la demande.

Des groupes éducatifs ou de thérapie ont traité d'une variété de problématiques et de sujets tels la gestion du stress et la relaxation, la socialisation, la résolution de problèmes, la stimulation, l'expression et l'affirmation de soi, le soutien pour personnes atteintes d'un traumatisme crânien, le soutien pour veufs et veuves. Des groupes de thérapie pour les femmes ayant été abusées sexuellement et de soutien pour les femmes vivant une séparation ont aussi été mis sur pied.

Les statistiques concernant la clientèle du CCSMPR au cours de l'année 1994 et s'intéressant aux facteurs du sexe, de la langue parlée, de l'âge, de l'état civil et de la source de référence démontrent que:

- $75 \%$ de la clientèle est féminine,

- $80 \%$ est francophone,

- $61 \%$ des gens ont entre 25 et 44 ans,

- $57 \%$ sont mariés,

- $16 \%$ sont célibataires,

- $17 \%$ sont divorcés,

- $6 \%$ sont veufs, et finalement que

- $68 \%$ font eux-mêmes une demande de service (sans être référés par un tiers).

Ces données statistiques sont fidèles à celles des années précédentes.

\section{Conclusion}

Compte tenu du fait que les politiques de soin de santé ontariennes semblent s'orienter vers une plus grande implication communautaire, nous verrons possiblement s'accroître le nombre de 
Reflets

centres de santé mentale avec une vocation semblable à celle du CCSMPR. Nous invitons toute personne oeuvrant dans un tel centre ou travaillant à sa mise sur pied, à échanger avec nous des idées, des réflexions ou des découvertes. 